\title{
Comparison between Diet and Body Mass Index in Geriatric type 2 Diabetes in Amravati Region
}

\section{Shital A Kale* and Rohankar PH}

Department of Zoology, Government Vidharbha Institute of Science and Humanities, Amravati, Maharashtra, India

\begin{abstract}
The Study was conducted using a single center in serial camps organized by Diabetic Association of India, Amravati Branch. Hundred patients of type 2 diabetes mellitus selected for study. Study of diet carried out by questionnaire about vegan and Non vegan, diet etc. and BMI with the help of standard formula. Fasting Blood Glucose (12 hour empty stomach) done by Glucose oxides peroxides method. We found the diabetes in male $14.01 \%$ high than that of female in case of non-vegan but higher obesity i.e. $17.26 \%$ was observed in female. Positive correlation between Body mass index and Fasting blood glucose was observed. The degree of correlation is found to be 1.7244 which is significant.
\end{abstract}

Keywords: Health, Health care; Diabetes type 2; Diet; Body Mass Index

\section{Introduction}

Geriatrics or geriatric Medicine is a specialty that focuses on health care of elderly people [1]. Elderly or older person, it should be either 50 or 55 years of age and above, but even this is somewhat arbitrary and introduce additional problems of data comparability across nations the more additional problem of data comparability across nations as per the more traditional definitions of an elder or elderly person correlate with the chronological age 50 to 65 years depending on the setting the region and the country [2].

Diabetes is a disease in which blood glucose or blood sugar, levels are too high glucose comes from the food we eat. Insulin is a hormone that helps the glucose get in to cells to give them energy with type diabetes, the more common type 1 diabetes, body does not make insulin. The body does not make or use insulin well without enough insulin, the glucose stays in the blood [3]. It can damage eyes, kidneys nerves and heart disease, stroke and even the need to remove a limb [3]. Type 2 diabetes develops gradually over a year the signs and symptoms are Fatigue, frequent urination, Excess, thirst, Blurry or cloudy vision wounds that won't heal, tingling or numbness in feet [4].

Type 2 diabetes mellitus is due primarily to lifestyle factors and genetics [5]. A number of lifestyle factors are known to be important to the development of type $2 \mathrm{DM}$, including obesity, lack of physical activity, Poor diet, stress and Urbanization [6].

A Fasting blood sugar level less than $100 \mathrm{mg} / \mathrm{dl}$ is normal. A fasting blood sugar level from 100 to $135 \mathrm{mg} / \mathrm{dl}$ is considered pre diabetes if its $126 \mathrm{mg} / \mathrm{dl}$ or higher is considered diabetic [7]. To control high blood sugar, not only taking the medicine is important, but also has to include best food in a diet for diabetes. Vegetables should eat in Diabetes low sodium fresh vegetables, roasted steamed and grilled vegetables are best, avoid a cooked vegetables with cheese, butter or sauce, cream Red meat fried meat, fried fish should be avoided with diabetes [8]. In the nurses' Health Study into red meat and processed meats were related to expanded danger of diabetes [9]. Over weight at age 25 year and BMI at 25, 35 and 45 years of age strongly associated with diabetes risk [10]. A more than normal BMI ranges raises the risk of heart diseases, stroke, kidney failure, nervous system and eyes problem with type 2 diabetic patients [11]. Proper diet and exercise are key components of management of type 2 diabetes [12]. Vegan or fruit mixed diets regularly to be higher in fiber which slows the rate sugar is soaking up into the blood stream. Switching people with diabetes to vegan diet decreased HbAlc abd LDL (Low density Lipoprotien), and may improve blood filterability [13].

Junk foods are high in calories and low in vitamins minerals and fiber junk food likewise commonly contains a lot of included sugar and high in saturated fats. With the goal that garbage nourishment to process all the more rapidly, which can build glucose levels and terrible cholesterol [14].

Overall, diabetes frequency is higher in rural India as $68 \%$ of population lives in villages and accept because of unaware or lack of medical care [15].

Experts think that the increasing fact of obesity and diabetes in India because of increased use of saturated fats, sugar and unawareness of exercise and that these changes are related to urbanization (Migration from Rural to Urban areas) [16].

\section{Material and Methods}

We selected 100 known geriatric male \& female diabetic type 2 patients from the diabetes camps and carried out the study on blood samples. The study was conducted in a single diabetes center of India in serial camps organized by diabetic Association, Amravati branch of India. Study of diet carried out by questionnaire about veg and Non veg, diet etc. and BMI with the help of standard formula, BMI=weigh in kilo/ height in MX Height in M [17] patients. Fasting Blood Glucose (12 hour empty stomach) done by Glucose oxides peroxides method [18].

The results were presented as a mean standard deviation. The correlation study between BMI and fasting blood glucose was done using Pearson's correlation test degree of correlation by coefficient correlation testing.

*Corresponding author: Shital A Kale, Department of Zoology, Government Vidharbha Institute of Science and Humanities, Amravati, Maharashtra, India, Tel: 07212531704; E-mail: kaleshital20@gmail.com

Received December 08, 2017; Accepted December 26, 2017; Published December 29, 2017

Citation: Kale SA, Rohankar PH (2017) Comparison between Diet and Body Mass Index in Geriatric type 2 Diabetes in Amravati Region. Health Econ Outcome Res Open Access 3: 144. doi: 10.4172/2471-268x.1000144

Copyright: $\odot 2017$ Kale SA, et al. This is an open-access article distributed under the terms of the Creative Commons Attribution License, which permits unrestricted use, distribution, and reproduction in any medium, provided the original author and source are credited. 
Citation: Kale SA, Rohankar PH (2017) Comparison between Diet and Body Mass Index in Geriatric type 2 Diabetes in Amravati Region. Health Econ Outcome Res Open Access 3: 144. doi: 10.4172/2471-268x.1000144

\section{Results}

Hundred subjects included in the study, Values obtained for Body Mass index Fasting Blood glucose shown in the Table 1.

The statistical analysis showed $78.33 \%$ diabetic male were found to be Non vegetarian and $21.67 \%$ diabetic male were found to be Vegetarian, while $64.32 \%$ diabetic female found to be Non vegetarian and $35.68 \%$ female found to be vegetarian, male $14.01 \%$ high than that of female in case of Non veg diet but, reverse result obtained in subject of obesity female $16.99 \%$ higher than male in case of obesity. Correlation analyzed by person's correlation we found the positive correlation between the Body Mass index and Blood glucose i.e., 0.11478 . Significant correlation observed by ' $\mathrm{t}$ ' test, i.e., 1.7244

\begin{tabular}{|c|c|c|c|c|c|}
\hline & Non Veg. & Veg & $\begin{array}{c}\text { Gody Mass } \\
\text { Index }\end{array}$ & $\begin{array}{c}\text { Correlation } \\
\text { Between BMI \& } \\
\text { Fasting Blood } \\
\text { Glucose }\end{array}$ & $\begin{array}{c}\text { Fasting } \\
\text { Blood } \\
\text { Glucose T } \\
\text { Value }\end{array}$ \\
\hline Male & $78.33 \%$ & $21.67 \%$ & $41.31 \%$ & 0.11478 & 1.7244 \\
\hline Female & 64.32 & $35.68 \%$ & $58.53 \%$ & - & - \\
\hline
\end{tabular}

Table 1: Diet relation of diet, body mass index, and fasting blood glucose. (calculated value) among the Blood glucose and geriatric type 2 diabetes patients.

Graphic representation of diet and body mass index in geriatric type 2 diabetes mellitus

The normal range of $\mathrm{BMI}$ is $0-25$ but people with diabetes who eat Non vegan diet will have Body Mass Index (BMI) of Male- 25-44 and Female BMI range 28-49, diabetic people who have vegan diet BMI range of male 22-27 and female range 20-31 shown in Figures 1-4 respectively.

\section{Discussion}

Our study was tabulated and compared with studies of other workers. The higher BMI was associated with incensed resistance and disease, insulin there for [5]. The consumption of red meat, particularly processed meat, increase the risk of insulin resistance type 2 Diabetes, whereas there is controversy over poultry [19]. Non veg consumption was positively associated with hyperglycemia, hyperinsulinemia, and insulin resistance in nondiabetic people, and that those associated was mainly dependent on

\section{Body Mass Index}

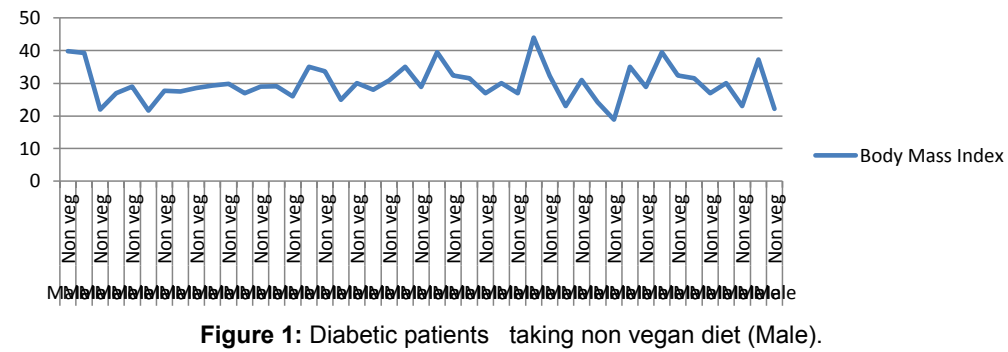

Figure 1: Diabetic patients taking non vegan diet (Male)

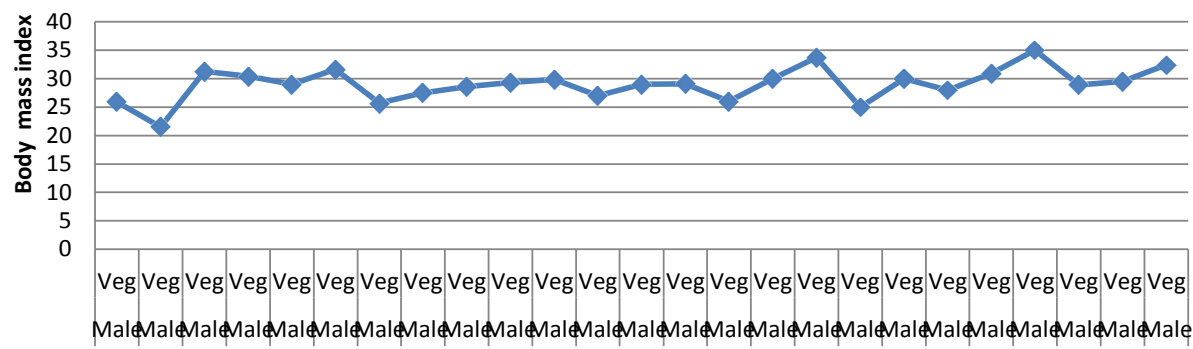

Figure 2: Diabetic patients taking vegan diet (Male)

\section{Body Mass Index}

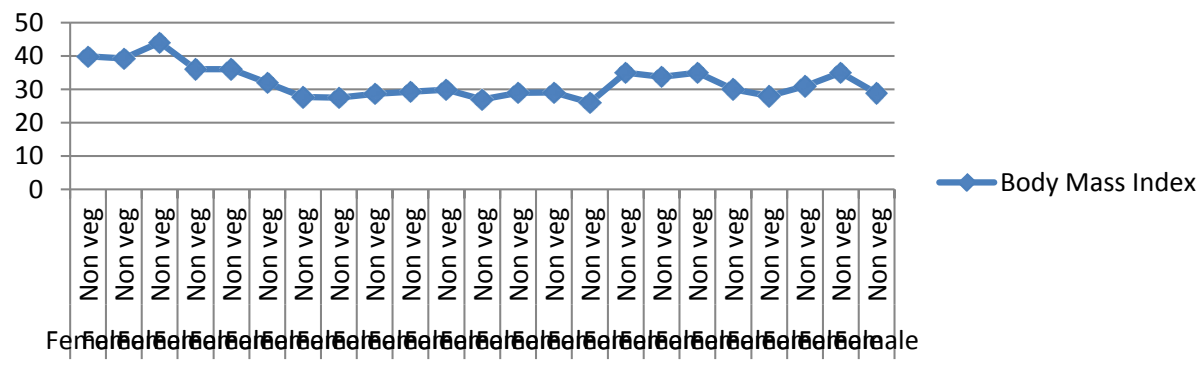

Figure 3: Diabetic patients taking non vegan diet (Female). 


\section{Body Mass Index}

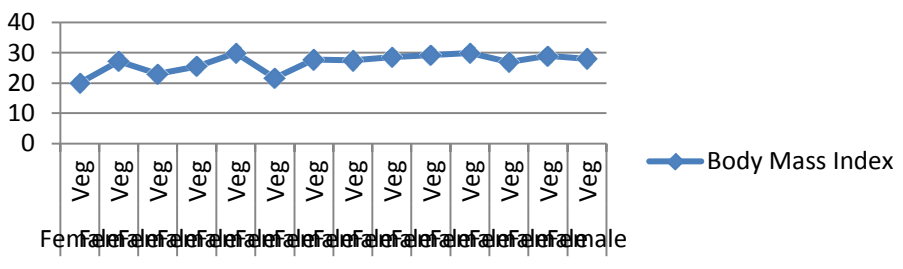

Figure 4: Diabetic patients taking vegan diet (Female)

BMI status [20]. Higher consumption of total meat may lead to insulin resistance and related chronic disease development, such as obesity, diabetes and cardiovascular disease [21]. Obesity is known to induce insulin resistance due to decrease in insulin-sensitive receptors as the weight increase [22]. Researcher on obesity have demonstrated an expanded weight list in elderly population, which requires consideration due to the risk of co morbidities that expansion with an expanded risk of mortality [23].

The burden of diabetes is much higher in the older population and is associated with more clinical complications than in younger people, however, valid data on the prevalence of type 2 diabetes in the elderly population are spares in Europe despite its enormous human and economic burden [24]. Vegetarian dietary patterns have been linked to numerous health benefits, including a lower risk of ischemic heart disease, hypertension, cancer and type 2 Diabetes and decreased BMI [25]. Diet, a lifestyle behavior has been reported as a management domain with very low compliance among diabetes [26]. The adoption of new food habits is not an easily achieved goal. Diabetic patients encounter several educational, environmental psychological and lifestyle difficulties in modifying their lives to accommodate disease management [27]. A healthy eating lifestyle resulted in low $\mathrm{HbAlc}$ levels and was positively related to specific food habits, i.e., limiting the amount of high- sugar foods and portion sizes, eating only an occasional desert, reducing high fat foods eating low- fat foods, eating regularly plan meals, limiting specific carbohydrate [28].

\section{Conclusion}

In the present study we found;

- Non vegetarian Diabetic male (\%) higher than Diabetic female in case of diet while Diabetic female higher (\%) than male in case of obesity.

- Positive correlation observed between Body mass index and fasting Blood glucose.

- Significant correlation observed among the, body mass index and fasting Blood glucose.

\section{Acknowledgments}

We would like to thank Diabetic Association, Amravati for giving us permission to undertake this study and their kind cooperation.

\section{References}

1. Medical School (2017) Geriatric separation and internal medicine university of Minnesota.

2. World Health Organization (2007) Definition of an older or elderly person.

3. Medline plus (2017) Diabetes US National library of medicine.

4. Erica O (2007) Type 2 Diabetes, Symptoms, Signs, Diet and Treatment medicine Net. Co.
5. Riserus U, Willett WC, Hu FB (2009) Dietary Fats and Prevention of Type 2 diabetes progress in lipid Research 48: 44-51.

6. Shlomo M, Kenneth P, Reed L, Henry SK (2011) Principles of Endocrinology Willams textbook of endocrinology philadephia Elsevire. pp: 1371-1435.

7. Mayo clinic staff (2014) Test and diagnosis mayo clinic

8. Mendon V (2014) Diet for diabetes Patient to control Blood sugar. Yoga: 168

9. Fug TT, Schalze M, Manson JE, Willett WC, Hu FB (2004) Dietary patterns meat intake and the risk of type 2 diabetes in women. Arch intern med 164 2235-2240.

10. Everhart JE, Pettitt DJ, Bennett PH, Knowler MC (1992) Duration of obesity increases the incidence of NIDDM diabetes 41: 235-240.

11. Vaz R (2017) Managing Type2 diabetes Does BMI matter Every day health.

12. Leontis LM (2017) Type 2 Diabetes and Exercise. Endocrine web.

13. Mccarty M (2002) Favorable impact of a vegan diet with exercise on path hemorhelogy implications for control of diabetes neuropathy 58: 476-486.

14. Linda $H(2016)$ Junk food and diabetes Health line pp: 1-5.

15. Khan HA (2016) Rural Population More Diabetic than Urban India BW BUSINESS WORLD. pp: 16.

16. Shah E, Kinra S, Bowen L, Andersen E, Shlomo Y, et al. (2010) The effect of rural to urban migration on obesity and diabets in India. Plos 7: 1371.

17. Magnsuon B (1998) How to calculate difference between body mass Index or $\mathrm{BMI}$ and diet. ExtoxNet.

18. Carl AB, Edward RA, David EB (2008) Diet 2 Fundamentals of clinical chemistry $6^{\text {th }}$ edn. pp: $3865-3867$

19. Nkondjock A, Recover O (2003) Fish- seafood consumption, obesity , and risk of type2 diabetes an ecological study 29: 635-642.

20. Glauber H, Wallance P, Griver K, Brechtel G (1998) Adverse metabolic effect of omega-3 Fatty acids in non-insulin dependent diabetes mellitus 108: 663-668.

21. Demosthenes BP, Natalia T, Chrustis P, Christina C, Emilia P, et al. (2005) The Relation between dietary Habits, Blood glucose and insulin levels among people without cardiovascular disease and Type 2 diabetes Reserch 2: 208-215.

22. Sue RW, Sara LA (1993) Nutrition and diet therapy. $7^{\text {th }}$ edn Mosby, USA

23. Lee IM, Manson JE, Hennekens CH, Paffenbarger RS (1993) Body weight and mortality. JAMA 270: 2823-2828.

24. Toutouzas K, Markou V, Drakopoul M, Mitropoulos I, Tsiamis E, et al. (2005) Patients with type 2 diabetes mellitus increased local inflammatory activation in culprits athermanous plaques $46: 283-288$.

25. Craig NJ, Mangles AR (2009) American Dietetic Association. Position of American diets. Amt Diet Assoc 109: 1266-1282.

26. Peyrot M, Rubin RR, Lauritzen T, Snoek FJ, Matthews DR, et al. (2005) Psychosocial problems and barriers to imoroved diabetes management: Result of the cross national diabetes Attitudes, Wishes and needs study. Diabetes Med 22: 1379-1385.

27. Snoek FJ (2000) Barriers to good glycemic control: the patient's perspective. Int J Obes Relat Metab Discord 24: 12-20.

28. Schmidt LE (1994) The relationship between eating patterns and metabolic control in patients with non-insulin dependent diabetic mellitus. Diabetes Edu 20: $317-321$ 